\title{
Universidades Comunitárias e sustentabilidade: desafio em tempos de globalização
}

\section{Communitarian Universities and sustainability: challenge in times of globalization}

\author{
Marilia Morosini* \\ Maria Estela Dal Pai Franco**
}

RESUMO

O trabalho analisa características de sustentabilidade na universidade comunitária - UC (não estatal orientada para a região), segundo seus gestores. Objetiva identificar políticas institucionais, mudanças no caráter comunitário e traçar perspectivas. Os conceitos de sustentação da mudança e de análise documental são basilares na análise e discussão. Os resultados mostram na UC as características de expansão, diversificação de áreas e de financiamento e estímulo acadêmico. Elas diferem quanto ao fortalecimento do grupo central e à cultura empresarial. O estudo conclui que o desafio é estabelecer mudanças sustentáveis e manter o caráter comunitário, independente de competições e recursos.

Palavras-chave: Universidade Comunitária; sustentabilidade; financiamento universitário.

\section{ABSTRACT}

This study analyses characteristics of the model of a sustainable university present in the community university (a regionally-oriented non-public school of higher education), according to its managers. Its purpose is to identify

\footnotetext{
* Professora da Pontifícia Universidade Católica do Rio Grande do Sul - PUCRS

** Professora da Universidade Federal do Rio Grande do Sul - UFRGS.
} 
MOROSINI, M.; FRANCO, M. E. D.P. Universidades Comunitárias e sustentabilidade...

institutional policies and establish perspectives. The concept of sustaining change and documental analysis is the basis for discussions. The results show expansion, diversification of knowledge areas and funding and stimulation of academic activities. The differences are the strengthening of the steering core and entrepreneurial culture. The challenge is to establish sustainable change and maintain the community character in spite of competition and resources.

Key-words: Community Universities; sustentability; university resources.

A década de 90 foi marcada por drásticas mudanças nas Instituições de Educação Superior (IES) brasileiras. As políticas públicas que caracterizaram a educação superior (ES) (1994-2002) assentaram-se em orientações do Banco Mundial, tais como: redução do papel do Estado, com ênfase no ensino privado; expansão do Sistema de Educação Superior (SES); descentralização, diversificação e flexibilização do SES; avaliação da ES ancorada em conceitos de qualidade isomórficos e orientados para a tomada de decisão e o controle de qualidade.

Embora as políticas brasileiras sinalizem, a partir de 2003, para o fortalecimento da missão pública e para o aumento de vagas na ES, as mudanças prévias tiveram forte impacto no SES. As agências multilaterais, como a mencionada, foram eficientes em "produzir o discurso da busca da produtividade e da eqüidade social, a partir de ajustes político-econômicos orientados por diretrizes neoliberais (...)" (SILVA JR., 2003,p.75). Neste contexto é de se supor que as IES busquem modelos alternativos que lhes garantam a sobrevivência. Entre estes, destacam-se o de Universidade Sustentável (CLARK, 2003), propagado nos países do norte, e o de Universidade Heterônoma (sGUISSARDI, 2003), em países em desenvolvimento. O trabalho tem como questão central identificar o(s) modelo(s) de universidade que prevalece $(\mathrm{m})$ nas Instituições de Educação Superior Comunitárias (UCs), ${ }^{1}$ na perspectiva de seus gestores. Os objetivos são: 1) analisar polí-

${ }^{1} \mathrm{O}$ estudo qualitativo (GRAwITZ, 1986) analisa UCs a partir de: 1) entrevistas com gestores; 2) documentos legais; e 3) estatísticas oficiais. As UCs participantes estão no RS, que tem 7 UCs privadas não confessionais, 3 UCs confessionais e um centro universitário. As 11 UCs representam 27,5\% das 40 UCs brasileiras. Os critérios de seleção dos entrevistados foram: exercício (presente/passado) de cargo na administração central da IES, participação nos órgãos superiores, e trajetória institucional que possibilite análise comparativa. 
ticas e práticas institucionais disponíveis nas UCs, tendo presente políticas educacionais e a influência da globalização; 2) identificar características e mudanças no caráter comunitário e possíveis razões; e 3) traçar perspectivas de gestores para as UCs frente à atual conjuntura.

\title{
A sustentabilidade na Universidade heterônoma brasileira
}

As lições sobre a universidade fornecidas pelo Banco Mundial (1998) marcam presença na ES de muitos países e encontram ressonância no trabalho desenvolvido por Clark. Este autor propõe, a partir de estudos de casos no mundo desenvolvido, um novo conceito de universidade, o modelo da sustentabilidade. As universidades

\begin{abstract}
... podem transformar-se em direção a um caráter altamente pró-ativo que está em grande parte sobre o seu próprio controle. (...) construindo um permanente estado orientado para a mudança e (...) fundamentam a organização sob duas capacidades: adaptar a si próprias e adaptar-se a uma sociedade em mudança. O desenvolvimento destas capacidades de mudança torna-se o cerne de um desempenho bem sucedido (CLARK, 2003, p. 115 ).
\end{abstract}

Este conceito vai além do empreendedorismo, pois implica mudança e sua sustentação. Ele é configurado por cinco eixos que mantêm a transformação e reforçam o ciclo pró-ativo, assim como por princípios da dinâmica da sustentabilidade que são marcados pela atitude de mudança contínua. Os eixos da sustentabilidade são:

- base diversificada de financiamento, que abarca três correntes de recursos: do Ministério ou departamento governamental, de fundos de conselhos governamentais de pesquisa e outros, também chamado de terceira corrente;

- núcleo central fortalecido, entendido como um time administrativo forte, desde o reitor até chefias de diferentes instâncias e níveis da universidade. Exige uma equipe sênior, com especialistas alta- 
MOROSINI, M.; FRANCO, M. E. D.P. Universidades Comunitárias e sustentabilidade...

mente qualificados (gerentes profissionais ao lado de professores);

- desenvolvimento até a periferia, entendido como exigência de novos formatos administrativos e organizacionais, com unidades que transponham os muros institucionais;

- coração acadêmico motivado, que exige vontade de mudar, de assumir riscos, de ser altamente pró-ativo e empreendedor, até mesmo num contexto hostil e questionador;

- cultura empreendedora integrada, que supõe trabalhar em comitês, fomentar a busca de recursos, desenvolver capacidade multidisciplinar para além dos muros da universidade e respeitar o comportamento empreendedor (CLARK, 2003, p. 101-108).

No âmbito brasileiro, Sguissardi (2003) destaca que a tese da existência de um modelo único na educação superior no país “(...) é uma verdadeira falácia. $\mathrm{O}$ que se pode afirmar e facilmente demonstrar é que se está em presença de uma dualidade ou superposição de modelos" (SGUISSARDI, 2003, p. 6). A IES brasileira seria tanto neonapoleônica, modelo compatível ao das escolas profissionais, como neo-humboldtiana, com estrutura de pesquisa e de Pós-graduação. Isto porque a legislação brasileira liberou as instituições da obediência ao principio da indissociabilidade de ensino, pesquisa e extensão, assim como da obrigação das entidades mantenedoras de publicar demonstrativos financeiros certificados por auditores independentes. Tais políticas levaram ao crescimento do modelo neoprofissional. Estaria ocorrendo a transição da universidade com autonomia (estaduais paulistas e privadas) e sem autonomia (federais, demais estaduais e municipais) para uma universidade heterônoma e competitiva, tendo presente que "o modelo de heteronomia significa o poder de setores externos - estado e indústria - na definição da missão, da agenda e dos produtos da universidade. É o mercado aumentando sua capacidade para impor sua própria lógica e interesses" (SGUISSARDI, 2003, p. 7).

Estas idéias adquirem sentido ao lembrar das peculiaridades das IES Comunitárias (UC) do RS, que se distinguem pela participação institucional efetiva de todos os segmentos na elaboração do planejamento estratégico e na tomada de decisões maiores. ${ }^{2}$ A certificação de UC não é indicador de

${ }^{2}$ As IES Comunitárias foram criadas na década de 1940 e consolidadas na década de 1980, totalizando, em 2004, 40 instituições (ABRUC, 2004). Elas representam 2,44\% das 
sustentável e heterônoma, mas abre a possibilidade de que tal ocorra. À letra da lei, ${ }^{3}$ abstraído o contexto, poderá sinalizar para um modelo tradicional, ligado estritamente aos compromissos e participações do local.

\section{Políticas e práticas nas UCs e globalização}

No cenário de tensões entre os modelos globalizantes e os princípios da IES comunitárias, foram identificadas políticas e práticas de expansão, diversificação e avaliação institucional para a qualidade. A característica mais marcante foi a da expansão.

Um gestor lembra que a IES cresceu à média de $15 \%$ ao ano (E1) e outro ressaltou que, de 1995 a 2003, a UC triplicou os 70 mil metros quadrados de área construída (E2). A expansão é estratégica na competição pela busca de alunos: ${ }^{4}$ (...) para não deixar entrar outras instituições privadas, nós acabamos construindo três campi (...) (E1).

A criação de novos cursos foi estratégia de inclusão, mantendo jovens na região. E3 apontou que a expansão é decorrente da incorporação de novos cursos, substituindo cursos (...) na área de Educação, que, na época, também estavam em decadência. Outra UC, de porte maior, ressalta

1.637 IES brasileiras (MEC/INEP, 2004), predominando universidades. O financiamento governamental tem sido cíclico: na década de 60 estavam nominadas no orçamento estatal; na década de 70 recebiam ajudas financeiras específicas, mas decrescentes; com a CRFB de 1988, passaram a receber novamente auxílio orçamentário; o que decai a partir dos anos 1990. Para a ABRUC - Associação de Universidades Comunitárias - a UC “(...) é uma universidade instituída, mantida e supervisionada por uma pessoa jurídica de direito privado, sem fins lucrativos, gerida por colegiados constituídos de representantes dos professores, alunos e funcionários e da sua entidade mantenedora, bem como da sociedade em geral" (VANUCCHI, 2003).

${ }^{3}$ A LDB, em seu Art. 20, considera como comunitárias “(...) as que são instituídas por grupos de pessoas físicas ou por uma ou mais pessoas jurídicas, inclusive cooperativas de professores e alunos que incluam na sua entidade mantenedora representantes da comunidade".

${ }^{4} \mathrm{O}$ gestor E1, explicando o crescimento assustador, afirma que “(...) nós sentimos a necessidade de fechar a região para outras instituições do RS, especialmente privadas, que estavam com uma política extremamente agressiva. (...) a concorrência nos obrigou a ter esse crescimento rápido, sob pena de ser engolido" (E1). 
MOROSINI, M.; FRANCO, M. E. D.P. Universidades Comunitárias e sustentabilidade...

como razão da expansão, o aprimoramento da qualidade da instituição, via PG: "Esses cursos foram profundamente benéficos às IES" (p. 3).

A diversificação, outra característica, tem várias faces, seja em relação aos níveis de educação, seja em relação aos motivos da diversificação. Para um gestor, a diversificação ocorreu na modalidade de cursos de PG, no oferecimento em áreas mais distanciadas da Pós-Graduação, como o Direito, e em áreas que a IES considerou estratégicas, como Comunicação Social, Enfermagem e Filosofia (E2, p. 2).

Outra face da diversificação alerta para a mercantilização do ensino: “(...) essa verdadeira extorsão que se pratica na população brasileira, na verdade (...) verdadeiras armadilhas caça-níqueis" (E1). Complementando, o gestor destaca que o país precisa reforçar o sistema de avaliação e de fiscalização e afirma que “(...) ou comprávamos [um hospital] ou a outra instituição particular que está na região compraria, para ser porta de entrada de cursos na área da saúde, e nós não podíamos permitir isso" (E1).

Os gestores são favoráveis ao processo de avaliação institucional. O gestor de uma UC pequena ressalta a preocupação de que "(...) a nossa instituição esteja obedecendo aos princípios que o MEC apregoa, porque, com certeza, hoje, o processo é muito sério" (E3). As razões para esta postura positiva sobre a política de avaliação do governo federal são diversas: a concepção de avaliação como controle ${ }^{6}{ }^{6}$ a concepção de avaliação como ranqueamento - eliminação de competidores ${ }^{7}$ e, numa visão mais ampla, inclui a avaliação da missão das UCs (relação com a comunidade). ${ }^{8}$ Para E2, o novo modelo exige que as IES atendam aos padrões internacionais. Nota-se a valorização da avaliação certificadora pela qual “(...) apenas

${ }^{5}$ O gestor reconhece a melhora de titulação do corpo docente: em 1995, 19,2\% dos professores eram mestres e apenas 2\% eram doutores. Em 2003 os mestres atingiram 41,4\% e os doutores aumentaram mais de sete vezes (14,8\%) (E2). O primeiro curso de PG (nas UCs) ocorreu em 1996. (...). Em 2003 são cinco programas (mestrado e um com doutorado) recomendados pela CAPES $(\mathrm{E} 2)$.

6 "E quem não estiver entendendo a seriedade e respondendo a este processo corre o risco de ser eliminado dele, e nós não podemos correr esse risco. Então, hoje, a preocupação nossa é com a instituição como um todo, não é só com o curso" (E3).

7 "Nós somos favoráveis à avaliação do ensino, porque queremos diferenciar a oferta de ensino com qualidade da oferta que não tem qualidade e se coloca no mercado para ganhar dinheiro" (E1).

8 "O importante é buscar a integração (da universidade) com sua comunidade, o que vem sendo muito perseguido pelas Unidades Acadêmicas (Institutos e Faculdades) através da atuação em atividades de extensão comunitária e pela organização de Centros, Núcleos, além do complexo de Bibliotecas" (E2, p. 2). 
as IES certificadas, à semelhança das empresas, poderão obter o devido reconhecimento" (p. 1-2). No entanto, E2 tem presente que “(...) não se pode avaliar o desempenho institucional apenas pelo desejo de atendimento a esses parâmetros".

\section{Caráter comunitário e tensões: sustentabilidade, transformação e mudança}

A discussão anterior mostrou que a UC Brasileira tem como uma de suas marcas e fonte de tensões a sustentabilidade. A tensão decorre da sua dupla natureza: o caráter público de serviço à comunidade, que tende a ser visto como oposto à sustentabilidade, e o caráter heterônomo e cambiante de sua inegável inserção num mundo globalizado, competitivo e em luta pela sobrevivência, que exige o empreendedorismo.

As UCs não apresentam um formato institucional único: “(...) embora as universidades comunitárias proclamem possuir uma identidade própria que as diferencia dos demais setores do ensino superior, esta identidade é um processo em construção, mais avançado em algumas, incipiente em outras" (BITTAR, 1999, p. 226).

Algumas estão próximas do modelo heterônomo e são reativas às investidas da globalização; outras sentem a influência da globalização, mas estão fortemente ligadas com o local através, especialmente, da formação dos quadros. O terceiro formato é uma simbiose dos anteriores: estão cientes do espaço da internacionalização e suas repercussões (cursos à distância por instituições estrangeiras), mas priorizam os valores locais e a comunidade. $\mathrm{O}$ primeiro formato adota o empreendedorismo reativo: “(...) nós buscamos sustentabilidade e precisamos do aumento de escolas para nos mantermos. Estamos atentos aos movimentos e faremos o que tivermos que fazer, sem perder o caráter comunitário" (E1).

O segundo formato institucional é calcado no local: “(...) enorme condição de ação na comunidade: isso se reflete no número de alunos entrando, na receptividade da comunidade por nossos egressos" (E3). "Trabalhar com a comunidade é essencial: (...) se não houver interferência [da universidade] para melhorar o meio, a universidade não pode existir. Então, universidade sem comunidade não acontece" (E3, p. 5). 
MOROSINI, M.; FRANCO, M. E. D.P. Universidades Comunitárias e sustentabilidade...

O terceiro formato é o do empreendedorismo e intercâmbio sem subserviência: “(...) a universidade não precisa apenas receber dos outros; ela já tem condições de oferecer convênios, pondo à disposição de IES nacionais e de outros países sua capacidade de conhecimento produzido" (E2, p. 3-4).

Ante a constatação da variedade de modelos, pergunta-se até que ponto os eixos da sustentabilidade, tal qual propostos, encontram espaço na universidade comunitária? Como a transformação e a mudança fazem presença nas universidades comunitárias e se conjugam com a heteronomidade? Os cinco eixos são analisados a seguir.

Os entrevistados mostram esforço institucional para obter uma base diversificada de financiamento, mas ressaltam a importância de recursos do governo federal. Um deles afirma que “(...) o movimento em relação ao FIES (Fundo de Financiamento do Estudante do Ensino Superior) foi deflagrado pelas comunitárias gaúchas, e está, agora, causando a mudança no FIES: a questão da recompra dos títulos da dívida pública. Isto partiu do Comung (Consórcio das Universidades Comunitárias Gaúchas)" (E1). Continuando, ele salienta que as IES públicas, não estatais, "têm que buscar recursos públicos para poder fazer um ensino de qualidade. Alunos não podem financiar pesquisa e extensão" (E1).

Outro entrevistado menciona práticas reveladoras da diversificação de financiamentos, incluídos recursos governamentais obtidos através dos Planos Regionais de Pesquisa e Pós-Graduação, com o apoio de agências governamentais federais e estaduais, de associações e da comunidade. É nítida a base diversificada de financiamento, assim como o envolvimento da comunidade, sob o horizonte da qualificação (E2).

Em relação ao núcleo central fortalecido e à gestão estratégica, são noções que vão além da administração central forte, mas se estendem aos vários níveis e instâncias de gestão, alcançando até os periféricos. A preocupação em fortalecer a gestão é aludida em todos os depoimentos. Um núcleo de gestão forte tende a ser visto no mesmo plano que a gestão estratégica. O Plano de Desenvolvimento Institucional (PDI) é compreendido como estratégico e via de fortalecimento. Para alguns, "a visão estratégica é continuar crescendo cada vez mais, uma instituição da comunidade, fiel, portanto, à nossa origem (...)" (E1). Trazem a questão da gerência profissional e da experiência de gestão, focalizando a busca de recursos externos (financiamento do BNDE, de órgãos financiadores públicos) e, ao mesmo tempo, certa visão estratégica de mercado, de enfrentamento. 
Outro entrevistado afirma que a falta de uma gestão fortalecida decorre da ausência de projetos, da falta de administradores abertos e com planos estratégicos de ações. A administração forte é consequiência da gestão de qualidade, de programas de qualidade incorporados no campus, “(...) com a visão de que temos que trabalhar em cima de dados, resultados, mas uma gestão participativa, uma gestão da validação de idéias, uma gestão da delegação de competências, uma gestão horizontal" (E3, p. 5).

No que tange ao desenvolvimento até a periferia, os entrevistados mostram menos preocupação com o estabelecimento de unidades/órgãos que vinculem universidade e comunidade e mais interesse em construir relacionamentos interinstitucionais, resultantes da diversificação de fontes de renda, por meio: a) da potencialização de relações com a comunidade pelo ensino, pois é difícil realizar atividades de pesquisa e extensão contando com o recurso de alunos; e b) do estabelecimento de elos com a comunidade pelo trabalho em rede e participação em fóruns. O primeiro, por meio do Comung, ou de projetos a ele ligados, buscando criar uma identidade estadual e de instituição comunitária na relação política com as outras IES (E1). O segundo, pela participação em associações e fóruns universitários como Abruc ${ }^{9}$ (nacional) e Comung (estadual), “(...) reafirmando sua identidade comunitária, buscando fortalecer a integração regional face às investidas de novas concorrentes (novas IES oriundas da iniciativa efetivamente privada), na modalidade de ensino presencial e à distância” (E2).

Ressalta-se a motivação do desenvolvimento identitário, do fortalecimento contra investidas das IES privadas propriamente ditas nas várias modalidades de oferecimento.

As UCs sinalizam para um coração acadêmico motivado. O estado de mudança estável requer a vontade de assumir riscos e ser pró-ativo. Nas UCs, o componente pró-ativo é encontrado em três vias: da qualificação, da internacionalização e da comunidade. Na via da qualificação, é ressaltado o esforço para atingir “(...) $87 \%$ dos professores com mestrado e doutorado, qualificação que vem desde 1983 e que sofre dificuldade para ter continuidade. A IES (...) tem um plano de carreira, hoje com mais de $50 \%$ de professores com horas para a pesquisa, ou extensão, ou gestão [decor-

${ }^{9}$ Associação Brasileira de Universidades Comunitárias - reúne instituições confessionais, além das comunitárias gaúchas: as PUCs, as metodistas, a Unisinos. "A estratégia, necessariamente, passou pela união dessas instituições, tendo em vista que congregação de comunitárias, tal qual no RS, não existe em outros estados, uma que outra em Santa Catarina, uma que outra em São Paulo” (E1). 
MOROSINI, M.; FRANCO, M. E. D.P. Universidades Comunitárias e sustentabilidade...

rendo] grande pressão na folha de pagamento. Nos tornamos [sic] uma instituição cara" (E1).

$\mathrm{Na}$ via da internacionalização, nota-se a estratégia de qualificação de professores e alunos em países da Europa, da América do Norte, do Mercosul e da África. Os convênios são realizados com países, especialmente, da Península Ibérica. O movimento de internacionalização é definitivo. Qualidade “(...) significa possibilitar a movimentação de alunos e de professores a outros centros internacionais. A formação mais completa é daqueles que têm vivência internacional" (E1). As UCs têm, no entanto, rechaçado a idéia de incorporação por grupos estrangeiros, que tentam comprar parte de uma UC.

Na via de trabalho com a comunidade é mencionado que “(...) sempre trabalhamos ligados à comunidade, nós somos parceiros da comunidade. Cada vez que tem qualquer atividade na cidade a universidade é chamada, ela faz parte dos conselhos" (E3, p. 4).

A cultura empreendedora integrada, último dos eixos da sustentabilidade, envolve capacidade para trabalhar por meio de comitês, estimular a busca de recursos e desenvolver capacidade multidisciplinar. A partir das entrevistas, a cultura empreendedora se manifesta no PDI, na diversidade de contatos externos e na idéia de compromisso.

A cultura empreendedora no PDI contempla maiores investimentos num planejamento estratégico que enraíze mais a universidade na região. Em 1995, a estrutura multicampi de uma das universidades já estava definida. Entretanto, “(...) levou uma década na consolidação dos cinco campi" (E1).

A cultura empreendedora na diversidade de contatos é encontrada no trabalho com outros países, como Moçambique, desvelando-se a preocupação com questões sociais: “(...) precisamos fazer um trabalho de internacionalização, buscando os grandes centros, mas também (...) aqueles centros que estão mais atrasados" (E2).

A cultura empreendedora que se expande em todos os níveis da universidade envolve a natureza da instituição: “(...) ser comunitária é um compromisso que precisa ser assumido pela gestão da instituição nos mais diversos escalões. É necessário que represente um desejo coletivo dos envolvidos, significando que a instituição assume essa direção como prioridade e ordena suas ações nessa perspectiva” (E2).

Os entrevistados mostram que a cultura empreendedora pode envolver a busca de recursos, mas esta é submetida à noção primeira de compromisso da UC. 
MOROSINI, M.; FRANCO, M. E. D.P. Universidades Comunitárias e sustentabilidade...

\section{Caráter Comunitário: mudanças e perspectivas}

As UC se defrontam, segundo seus gestores, com inúmeras tensões que exigem mudanças de orientação e de estratégias para a sobrevivência. Além de pontuá-las, é possível traçar, a partir das entrevistas e de manifestações da Abruc (2003), algumas perspectivas de gestores frente à atual conjuntura. As principais tensões são:

- dificuldade de serem "vistos": o governo federal e o MEC, especificamente, desconhecem o segmento comunitário, apesar de existir na Constituição (E1);

- não reconhecimento dos impasses enfrentados pelas UCs públicas, não estatais, que muitas vezes cumprem o papel do Estado onde inexistiria ensino superior (E2);

- dificuldades em manter ensino superior de qualidade e acessível, com mensalidades apropriadas, a alunos oriundos de classes sociais menos favorecidas. O caráter filantrópico de suas atividades de extensão continua sendo contestado pela União (E2);

- não reconhecimento de que, mesmo frente à crise econômicofinanceira e do acirramento da dependência ao global, essas universidades continuam crescendo, sendo possível bem administrálas, sem submetê-las ao mercado. Por vezes são mantidas áreas deficitárias porque eliminá-las provocaria a exclusão de camadas menos privilegiadas a esse nível de ensino (E2).

Algumas perspectivas são vislumbradas pelos gestores na atual conjuntura:

- defesa da identidade comunitária. Isto significa a aspiração pelo reconhecimento, mas ancorado em sua missão e seu espírito público. É a “[...] defesa de uma identidade que precisa ser não apenas mais conhecida e reconhecida dentre outras e sim porque a universidade comunitária se encontra revigorada em sua missão de forjar, através de forte integração e abertura à comunidade, um maior espírito público dentre os cidadãos que nela buscam sua formação" (E2); 
MOROSINI, M.; FRANCO, M. E. D.P. Universidades Comunitárias e sustentabilidade...

- pressão por Políticas Públicas que regulamentem e delimitem o SES e as relações IES-governo. É a luta para que o modelo comunitário seja reconhecido:

\begin{abstract}
... O governo federal precisa parar de combater os segmentos, que não o público (...) se não houver uma forte regulamentação nós corremos o risco de as instituições comunitárias sumirem, porque elas não têm a agressividade das universidades privadas, não se movem com essa lógica de mercado, porque fazem pesquisa. É fundamental que o governo pense essas relações: a regulamentação da expansão do Ensino Superior (E1).
\end{abstract}

Outras perspectivas são mencionadas: a) respeito pelas universidades públicas, mas com o questionamento de seu modelo, que deve ser transparente e a serviço da sociedade como um todo, permitindo, também, o acesso das classes mais necessitadas; b) diminuição de custos, pois os recursos via expansão de alunos estão no limite; c) resgate do projeto de educação popular (associações de moradores, formação de lideranças sindicais e também de movimento social urbano e rural); d) fortalecimento da relação com o setor produtivo: empresas da região, grupos organizados (ONGs), sindicatos, cooperativas e Estado.

É elucidativa a assertiva de um entrevistado ligado a uma UC que oferece cursos de Pós-Graduação e desenvolve pesquisa. E2 afirma que a UC jamais deverá assumir

o caráter empresarial a serviço de uma instituição privada a serviço apenas do cliente que puder pagar por sua formação, entrando na linha das empresas no ramo dos negócios educacionais. Essa poderia ser a resposta mais lógica, necessária, frente ao modelo instrumental da sociedade regido pelo princípio do mercado e, certamente, esperada senão desejada por muitos mesmo dentro das universidades comunitárias. Cortar-se-iam as áreas deficitárias e se garantiria a eficiência orçamentária. (...) Seria uma adequação às expectativas, porém, profundamente injusta, porque provocadora da exclusão das camadas menos privilegiadas desse nível de ensino [E2]. 


\section{Encaminhamentos conclusivos}

O qualificativo "comunitária" não tem sentido exclusivo e unívoco. Existem práticas comuns entre as universidades comunitárias, mas, também, diferenças na gestão. A expansão, a diversificação e a avaliação mostram a inserção no mundo globalizado.

A expansão ocorre em todos os níveis, inclusive em territórios geográficos de IES. Ela é ligada à competição interinstitucional na ocupação de espaços; à manutenção de jovens na região, utilizando novos cursos para a inclusão e reforçando o caráter comunitário; e à incorporação de novos cursos, substituindo os decadentes. O estágio da cooperação interinstitucional também é de expansão, mas sem subserviência. Já a diversificação responde à demanda e à competição interinstitucional, em áreas distanciadas da Pós-Graduação e em áreas que a IES considerou estratégicas para a sua consolidação. Os gestores alertam para a diversificação que mercantiliza o ensino, verdadeira armadilha.

Os gestores das UCs adotam uma postura positiva sobre a política de avaliação. Seu horizonte é a avaliação da missão das UCs. Não eliminam o controle assentado em padrões de qualidade e de qualificação, mas alertam para a exclusão. O país precisa de um sistema de avaliação, mas eles lembram que, além de fiscalização, o governo deve prover financiamento que possibilite ao aluno pagar em trabalho.

A maior fonte de tensões é a sustentabilidade institucional no confronto da dupla natureza da IES: o caráter público não-estatal, de serviço à comunidade e o caráter de sua inserção no mundo competitivo e em luta pela sobrevivência. Sob tal tensão, algumas IES se aproximam do modelo heterônomo, adotando um empreendedorismo reativo às investidas da globalização; outras captam tenuamente a influência da globalização, devido à forte ligação com o local que toma todo o olhar. Outras ainda estão atentas às repercussões da globalização, sem deixar de priorizar os valores locais e a comunidade.

Em relação à sustentação de mudanças, os eixos estão presentes, mas assumem peculiaridades da condição de UCs. Os entrevistados aspiram a uma base diversificada de financiamento, mas ressaltam a importância de recursos do governo federal. Eles se defrontam com dificuldades financeiras, mas têm expectativa de financiamento de projetos. Um núcleo central forte tende a ser visto no mesmo plano que a gestão estratégica. O PDI, a 
MOROSINI, M.; FRANCO, M. E. D.P. Universidades Comunitárias e sustentabilidade...

gerência profissional e a experiência de gestão são estratégicos e vias de fortalecimento na busca de recursos externos.

As IES buscam construir relacionamentos interinstitucionais por meio da potencialização de relações com a comunidade pelo ensino, do estabelecimento de elos com a comunidade pelo trabalho em rede (Comung) e da participação em fóruns. O componente pró-ativo, próprio de um cerne acadêmico motivado, com vontade de assumir riscos, é encontrado em três vias: da qualificação, da internacionalização e da comunidade. A cultura empreendedora integrada se manifesta no PDI, na diversidade de contatos e na idéia de compromisso que se incorpora e se expande em todos os níveis institucionais. As práticas apontadas se aproximam do modelo de mudança sustentável. Para Clark (2003, p. 23), existem dois milagres na transformação deliberada da universidade: iniciar a mudança, enfrentando o medo do fracasso, e sustentar o círculo virtuoso do sucesso. As UCs parecem reunir condições que potencializam a sustentação de mudanças.

As UCs têm se defrontado com limitações que exigem mudanças de orientação e de estratégias para a sobrevivência. Além da dificuldade de serem "vistas" pelo governo federal, não existe o devido reconhecimento dos impasses enfrentados pelas UCs públicas não-estatais que fazem o papel do Estado. Ainda existem dificuldades em manter o ensino superior de boa qualidade e acessível a alunos e classes sociais menos favorecidas.

As perspectivas vislumbradas pelos gestores das UCs frente à atual conjuntura centram-se na defesa da identidade comunitária, isto é, na aspiração pelo reconhecimento, ancorado na missão e espírito público; na pressão por Políticas Públicas que regulamentem e delimitem o SES e as relações IES-governo e respeito pelas universidades públicas; resgate de projetos sociais e do fortalecimento da relação com o setor produtivo. Eles vislumbram, ainda, o aumento de tensões entre práticas tradicionais das universidades comunitárias e novas estratégias assumidas para a sustentabilidade da instituição, incluindo competição pela captação de recursos e demandas, bem como resquícios de práticas históricas, principalmente quanto ao financiamento destas IES pelo Estado.

Na década de 1990, a IES passou de um ethos fundamentado na obtenção de recursos governamentais para a diversificação de fontes de financiamento. Tal mudança, no entanto, não é do caráter comunitário, mas reconhecem os gestores a necessidade de medidas de fortalecimento do mesmo. Certamente existem implicações.

A acentuada expansão pode gerar o esgotamento da demanda de alunos com condições de financiar o ensino superior, comparando dados so- 
bre faixas de rendimento da população e o número de famílias que podem suportar os encargos de membros freqüentando este nível. Pode, inclusive, acirrar a competição interinstitucional, em níveis que extravasam o do estímulo para cair em jogos nefastos de intriga e maledicência.

A diversificação de áreas de conhecimento, inclusive inovadoras no sentido de um primeiro oferecimento na região, pode implicar escolhas precipitadas, sem a devida preparação de quadros de pessoal para atender o ensino e a pesquisa.

A busca de novas fontes de financiamento abre portas para o empreendimento, mas pode submeter a universidade às formas mercantilistas, neutralizando a missão maior de serviços. Pode ser mera resposta competitiva que antecipe ações de outras universidades. Inclusive as universidades menores e menos complexas criticam as grandes universidades confessionais que têm disponível uma ampla gama de alternativas de financiamento (desde hospitais até estacionamentos), mas que se classificam como comunitárias.

O estímulo à cultura do empreendedorismo, além de alicerçar o desenvolvimento regional, pode degenerar em individualismo. $\mathrm{O}$ fortalecimento do centro administrativo institucional pode ultrapassar, em nome da eficiência, os limites de uma construção democrática, sempre mais penosa e demorada do que o centralismo decisório.

A separação entre a manutenção e a gerência da universidade gera tensões e dualidade de ações. Fica claro ao longo do trabalho que as universidades ainda estão construindo o caminho que as torna sustentáveis, na ótica de uma cultura contínua de mudança, ancorada nas vontades políticas da introdução de inovações, que tenham presente a qualidade, mas, também, a missão maior da universidade, que envolve a produção e o uso do conhecimento como um serviço ao público.

\section{REFERÊNCIAS}

ABRUC, Associação Brasileira de Universidades Comunitárias . Dados Informacionais. Disponível em: <www.abruc.org.br>. Acesso em: 01 de abril de 2004.

BRASIL. PRESIDÊNCIA DA REPÚBLICA. Lei $n^{\circ}$ 9.394, 20 de dezembro de 1996. Estabelece as diretrizes e bases da educação nacional. Publicada no D.O.U. em 23/12/ 
MOROSINI, M.; FRANCO, M. E. D.P. Universidades Comunitárias e sustentabilidade...

1996, p. 27.833-27.841. Disponível em: <http://www.mec.gov.br/ legis/default.shtm.>. Acesso em: 10 out. 2003.

BRASIL. MEC/INEP/SEEC. Censo do Ensino Superior, 2002. Brasília, INEP, 2003. Disponível em: <http// www.inep.gov.br>. Acesso em: 23 jun. 2003.

BITTAR, M. Universidade comunitária: uma identidade em construção. São Carlos, 1999. Tese (Doutorado em Educação) - Programa de Pós-Graduação em Educação, Universidade Federal de São Carlos.

CLARK, B. R. Sustaining Change in Universities: Continuities in Case Studies and Concepts. Tertiary Education and Management. The Netherlands, v. 9, n. 2, 2003, p. 99116.

GRAWITZ, M. Le Techniques au service des sciences sociales (Livro III). In: PINTO, Roger; GRAWITZ, Madeleine. Méthodes des Sciences Sociales. Paris: Livrairie Dalloz, 1986.

SGUISSARDI, V. A universidade neo-profissional, heterônoma e competitiva. In: REUNIÃO ANUAL ANPED, 26., Poços de Caldas, MG, 5-8 de out. 2003. (Completo em CD-Rom)

SILVA, Jr., J. R. Reforma da educação superior: a produção da ciência engajada ao mercado e de um novo pacto social. In: DOURADO, L.F. et al. Políticas e gestão da educação superior. São Paulo, Xamã, 2003, p. 53-80.

VANNUCCHI, A. Universidade Comunitária: O que é e como funciona. Disponível em <http://www.abruc.org.br/artigos>. Acesso em: 23 de fev. de 2003.

Texto recebido em 15 fev. 2006

Texto aprovado em 07 abr. 2006 